Modeling, Identification and Control, Vol. 37, No. 1, 2016, pp. 31-40, ISSN 1890-1328

\title{
Automated Kick Control Procedure for an Influx in Managed Pressure Drilling Operations by Utilizing PWD
}

\author{
Jing Zhou ${ }^{1}$ Jan Einar Gravdal ${ }^{2}$ Per Strand $^{3}$ Svein Hovland ${ }^{4}$ \\ ${ }^{1}$ Department of Engineering Sciences, University of Agder, N-4898 Grimstad, Norway. E-mail: jing.zhou@uia.no \\ ${ }^{2}$ International Research Institute of Stavanger, N-5008 Bergen, Norway \\ ${ }^{3}$ Statoil ASA, Bergen, Norway \\ ${ }^{4}$ National Oilwell Varco, Stavanger, Norway
}

\begin{abstract}
Within drilling of oil and gas wells, the Managed Pressure Drilling (MPD) method with active control of wellbore pressure during drilling has partly evolved from conventional well control procedures. However, for MPD operations the instrumentation is typically more extensive compared to conventional drilling. Despite this, any influx of formation fluids (commonly known as a kick) during MPD operations is typically handled by conventional well control methods, at least if the kick is estimated to be larger than a threshold value. Conventional well control procedures rely on manual control of the blow out preventer, pumps, and choke valves and do not capitalize on the benefits from the instrumentation level associated with MPD.

This paper investigates two alternative well control procedures specially adapted to backpressure MPD: the dynamic shut-in (DSI) procedure and the automatic kick control (AKC) procedure. Both methods capitalize on improvements in Pressure While Drilling (PWD) technology. A commercially available PWD tool buffers high-resolution pressure measurements, which can be used in an automated well control procedure. By using backpressure MPD, the choke valve opening is tuned automatically using a feedback-feedforward control method.
\end{abstract}

The two procedures are evaluated using a high fidelity well flow model and cases from a North Sea drilling operation are simulated. The results show that using AKC procedure reduces the time needed to establish control of the well compared to DSI procedure. It also indicates that the AKC procedure reduces the total kick size compared to the DSI procedure, and thereby reduces the risk of lost circulation.

Keywords: Well Control, MPD, Kick, PWD

\section{Introduction}

During drilling operations, there are many events that can evolve rapidly and have large consequences related to the flow of drilling fluid in the well. Fluid influx is one of these, which if not properly handled in due time, may lead to very dangerous and very expensive situations. Eliminating or minimizing drilling fluid influx reduces costs, improves safety, increases well bore stability, and decreases formation damage. Therefore, 
it is of great importance to control it in its early phase, so that it can be attenuated in a controlled manner.

Recent experience indicates that in order to optimize the drilling operation the entire drilling system, not just the mechanics or software, needs to be designed from a control system point of view. Automatic control of drilling operations in a well can be a challenging task, due to the very complex dynamics of the multiphase flow potentially consisting of drilling mud, oil, gas and cuttings. Managed Pressure Drilling (MPD) is a technology that enables precisely control of the annular pressure during drilling and aims to prevent drilling related problems in Hannegan et al. (2004). Constant bottomhole pressure control, one of the methods within MPD, utilizes a pressurized drilling system with a rotating control head and a surface choke to precisely control the wellbore pressure. Using this method, the bottomhole pressure can be more easily maintained within the bounds of a narrow porepressure to fracture-pressure gradient window.

Manual control of the choke valve in well control is commonly applied in today's drilling operations. The control systems are operated by the drilling crew, where the various inputs to the drilling system are adjusted independently. Therefore, it is low reaction to changes in set-point and disturbances. Proportional-IntegralDerivative (PID) control is a powerful control method because of the simple parameter tuning and limited requirements for knowledge about the process. PID control in the drilling process has been studied in Godhavn (2009), Zhou and Nygaard (2010) and Siahaan et al. (2014). Based on the developed drilling model, the model-based control for drilling operation has been studied in Nygaard et al. (2007), Carlsen et al. (2008), Breyholtz et al. (2009), Zhou et al. (2009), Zhou et al. (2010), Zhou et al. (2011), Zhou and Nygaard (2011), Kaasa et al. (2013). However, this method depends on the accuracy of the model and the complexity is increased by the fact that a large set of parameters in such models are uncertain or unknown and possibly changing.

The concept of MPD using annulus backpressure has partly evolved from conventional well control procedures. However, for MPD operations the instrumentation is typically more extensive compared to conventional drilling. Despite this, a kick incident during MPD operations is typically handled by conventional well control methods, at least if the kick is estimated to be larger than a threshold value. Conventional well control procedures rely on manual control of the blow out preventer, pumps, and choke valves and do not capitalize on the benefits from the instrumentation level associated with MPD. As a result of the ability to manipulate backpressure, MPD offers the capability to control a kick dynamically without shutting in. Once an influx is detected during MPD, an important decision is whether to control the well dynamically or to revert to conventional well control techniques. Automatic well control without shutting in is only applicable up to a certain size, rate, and duration of influx. The influx must be sufficiently small that it is within the limits of MPD surface equipment to circulate the influx out safely while maintaining well control.

Dynamic well control during MPD has been of interest in the literature for many years. Santos et al. (2003) and Santos et al. (2007) presented a Micro-flux control method, which is the monitoring and adjustment of return flow to control influx during drilling operations. The alternative initial responses to kicks during MPD were explored in Bacon et al. (2012); Davoudi et al. (2011); Smith and Patel (2012), by increasing casing pressure until flow out equals flow in. There is a significant potential to improve existing methods, and in what follows we propose a controller that automatically attenuates a kick without shutting down the pumps.

In this paper, we investigate two alternative well control procedures specially adapted to backpressure MPD: The dynamic shut-in procedure and the automatic kick control procedure. Both methods capitalize on improvements in Pressure While Drilling (PWD) technology. A new commercially available PWD tool buffers high-resolution pressure measurements, which can be used in an automated well control procedure. Typically, only minimum, maximum and average downhole pressure is transmitted to surface after circulation is regained. Using new PWD technology, recorded measurements at $0.5 \mathrm{~Hz}$ can be transmitted after regaining circulation. By using backpressure MPD, the choke opening is automatically controlled using a feedback-feedforward control method.

The rest of the paper is organized as follows. The second section presents the two kick control procedures. In the third section, the control theory is proposed. Results from case study are presented in the fifth section and finally the conclusions are drawn in the sixth section.

\section{Kick Control Procerures}

This section presents two well control procedures used in this paper, namely, the dynamic shut-in (DSI) procedure and the automatic kick control (AKC) procedure. In the DSI procedure, both the mud pump and the backpressure pump are shut down automatically and the well is shut in by closing the MPD choke valve. In the $\mathrm{AKC}$ procedure, circulation is maintained, resulting in less pressure variations in the annulus and the choke line system. 


\subsection{Dynamic Shut-in Procedure}

The DSI procedure is a method for attenuating a kick and controlling bottomhole pressure by adjusting the mud pump, backpressure pump and MPD choke valve. When using an automatic control system during the drilling operation, the bottomhole pressure is kept constant at a set-point defined by the driller.

An indicator that a kick has occurred is an increase in mudflow out of the well. The proposed system monitors the flow out vs. flow in and activates the kick control procedure. Immediately after the kick detection, the system starts the DSI procedure by closing the mud pump and backpressure pump while the choke valve is controlled by keeping the bottomhole pressure at a set-point. When the mud pump flow rate is less than a threshold value, the choke valve is closed completely. During the time when the pumps and the choke are fully closed, the well pressure will increase and balance the pore pressure of the influx zone. During this sequence the standpipe pressure, choke pressure and PWD measurements are recorded for later use as part of the pore pressure estimation of the reservoir kick zone.

After shut-in the circulation procedure starts by increasing the backpressure pump rate to the setting, which is the same rate before the kick situation began, and increasing the mud pump to a pre-determined slow circulation rate, $600 \mathrm{l} / \mathrm{min}$ while the choke valve is controlled by keeping the choke pressure at a calculated value. The PWD tool has an activation flow rate, which we have set to $600 \mathrm{l} / \mathrm{min}$. The mud pump rate is kept at a constant value for 5 minutes to transmit the recorded PWD measurements. After that, the mud pump rate is increased to the setting, which is the same rate before the kick situation began, and the choke valve is controlled by keeping the bottomhole pressure at a new set-point, which corresponds to the estimated pore pressure of the reservoir zone. Since the well is completely shut in during the pressure buildup, the new set point can be found using e.g. the pore pressure estimation method proposed by Gravdal et al. (2010).

\subsection{Automatic Kick Control Procedure}

Immediately after the kick detection, AKC automatically starts to increase the BHP by using the MPD choke control system. The choke valve is automatically controlled by balancing the flow-in and flow-out, resulting in reduced influx from the reservoir. The proposed response involves reducing flow out until equal to flow in, followed by maintaining this condition of fluid continuity for some time. The duration for this condition will be based on the confirmation that the influx has ceased to flow and experience. This phase is similar to the Micro-flux control method by Santos et al. (2003) and Santos et al. (2007). At the same time, the flow rates through the mud pump and backpressure pump are maintained at the initial values. When the pressures have stabilized and the flow-out vs. flowin balance is re-established, the bottomhole pressure is recorded for calculation of pore pressure of the reservoir zone. Then the choke valve is controlled by keeping the bottomhole pressure at a new set-point, which is higher than the estimated pore pressure of the reservoir zone.

\section{Feedback-Feedforward Control}

In this section, the automatic control method is described, where a feedback Proportional-Integral control and a feedforward control are applied. By using backpressure MPD, the choke valve opening is controlled automatically using a feedback-feedforward control method while the main pump flow and the backpressure pump flow are manually operated. The proposed control scheme can be described by the structure in Figure 1, where the feedback controller calculates an error value as the difference between a measured process variable and a desired set-point. The controller attempts to minimize the error by adjusting the process by use of a manipulated variable and compensate the effects of the disturbance. The disturbance consists of known and unknown disturbances, where the flows through the main pump and the backpressure pump are regarded as measured disturbances to the process.

The proposed feedback-feedforward control is expressed as

$$
\begin{aligned}
u(k)= & u_{P I}(k)+u_{f f}(k) \\
u_{P I}(k)= & u_{P I}(k-1)-K_{P}(e(k)-e(k-1)) \\
& -K_{I} e(k) \\
u_{f f}(k)= & K_{f f} d(k) \\
e(k)= & y(k)-y_{s p}
\end{aligned}
$$

where the control input $u(k)$ is the choke valve opening designed by combining a feedback control $u_{P I}(k)$ with a feedforward control $u_{f f}(k), e(k)$ is the error value as the difference between a measured process variable $y(k)$ and a desired set-point $y_{s p}, d(k)$ is the disturbance, the proportional gain $K_{P}$, integral gain $K_{I}$, and feedforward gain $K_{f f}$ are three positive constants chosen by the designer. By tuning the three parameters in the controller algorithm, the controller can provide control action designed for specific process requirements.

For our case, the disturbance variable $d(k)$ is consid- 
ered as the change of flowrates, such as

$$
\begin{aligned}
d(k)= & q_{\text {pump }}(k)-q_{\text {pump }}(k-1) \\
& \left.+q_{\text {back }}(k)-q_{\text {back }}(k-1)\right)
\end{aligned}
$$

In the $\mathrm{AKC}$ procedure, the process variable $y(k)$ is set to be the downhole pressure BHP during the constant bottomhole pressure control, such as

$$
\begin{aligned}
y(k) & =B H P(k) \\
y_{\text {set }} & =B H P_{s p}
\end{aligned}
$$

During the kick handling in the AKC procedure, we set the process variable $y(k)$ to be the flowrate, such as

$$
\begin{aligned}
y(k) & =q_{\text {pump }}(k)+q_{\text {back }}(k) \\
y_{\text {set }} & =q_{\text {choke }}(k)
\end{aligned}
$$

The objective is to rapidly balance the flow in and out of the well by automatically controlling the MPD choke, resulting in reduced influx from the reservoir. In order that the AKC procedure is effective and the flow control does not lead to too high BHP, the time keeping flow-in equals flow-out should be limited. Therefore, we have a pre-defined time window when using flow control. In the DSI procedure, the process variable $y(k)$ can be set as the measured downhole pressure $B H P$ during constant bottomhole pressure control and mud mump pressure $P_{\text {pump }}$ or the choke pressure $P_{c}$ during times with the low flowrate circulation, such as starting-up of the pumps.

In practice, the PID controller will be reduced to a PI controller in a field implementation since the derivative term is sensitive to measurement noise. The PI controller is a closed-loop feedback controller widely used in industrial control systems. One advantage of PI control is that it requires little knowledge about the process such that a process model is not necessary. Another advantage of PI control is its simplicity of structure and ease of implementation. In the absence of knowledge of the underlying process, a PI controller has historically been considered the best controller. By tuning the two parameters in the PI controller algorithm, the controller can provide control action designed for specific process requirements. The response of the controller can be described in terms of the responsiveness of the controller to an error, the degree to which the controller overshoots the set point, and the degree of system oscillation. PI controllers, when used alone, can give poor performance when the PI loop gains must be reduced so that the control system does not overshoot or oscillate around the control set-point value. They also have limitations in the presence of nonlinearities, such as have longer response time and have lag in responding to large disturbances.

The control system performance can be improved by combining the feedback control of a PI controller with feed-forward control. Knowledge about the system (such as the impact from changes of pump rate) can be utilized and combined with the PI output to improve the overall system performance. The feed-forward value alone can often provide the major portion of the controller output. The PI controller primarily has to compensate whatever difference or error remains between the set-point and the system response to the open loop control. Since the feed-forward output is not affected by the process feedback, it can never cause the control system to oscillate, thus improving the system response without affecting stability. Feed-forward can be based on the setpoint and on extra measured disturbances.

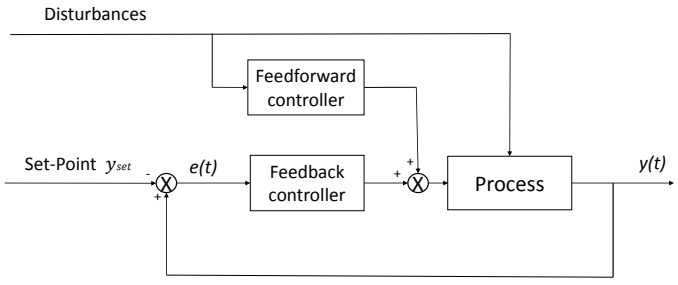

Figure 1: Feedback-Feedforward Control structure.

\section{Case Studies}

In this section, the two alternative well control procedures, DSI and AKC, are evaluated using a high fidelity well flow model WeMod Lage et al. (2000), which is a high fidelity drilling simulator developed by the International Research Institute of Stavanger (IRIS). WeMod solves a set of partial differential equations for transient two-phase flow referred to as the drift-flux formulation Lorentzen and Fjelde (2005). To illustrate the use of the proposed well control procedures, a drilled gas-kick situation is considered. MPD is simulated when drilling into a permeable formation containing gas and with higher pore pressure than expected. An indicator that a kick has occurred is an increase in mud flow out. The influx is assumed to be detected by some kick-detection method. The detection methodology is not the focus of this work.

The MPD setup for this work is a traditional automatic annular backpressure control system with backpressure pump, as shown in Figure 2. The drilling 
equipment consists of an MPD choke manifold including a high accuracy flow meter, main mud pump, and annulus backpressure pump. The annulus is pressurized by a rotating control device and the pressure can be controlled by adjusting the opening of the surface choke valve. A surface backpressure pump gives additional flow rate through the choke. By utilizing a PWD tool, the downhole measurement is transmitted every 20 seconds when the pump flow rate is above 600 $\mathrm{l} / \mathrm{min}$. There is no transmitted data during times with low flow rate (less than $600 \mathrm{l} / \mathrm{min}$ ) and no circulation. However, the PWD tool will automatically record pressure every 2 seconds when the flow rate is lower than $600 \mathrm{l} / \mathrm{min}$. Using the PWD technology, recorded pressure measurements at $0.5 \mathrm{~Hz}$ can be transmitted after regaining circulation. Thus, the PWD tool records and transmits full pressure data during that period. The transmission time for the recorded data after resuming circulation above $600 \mathrm{l} / \mathrm{min}$ is 5 minutes.

For the entire simulation, the choke valve is controlled automatically by the feedback-feedforward control algorithm described above. Two example wells are considered in this paper.

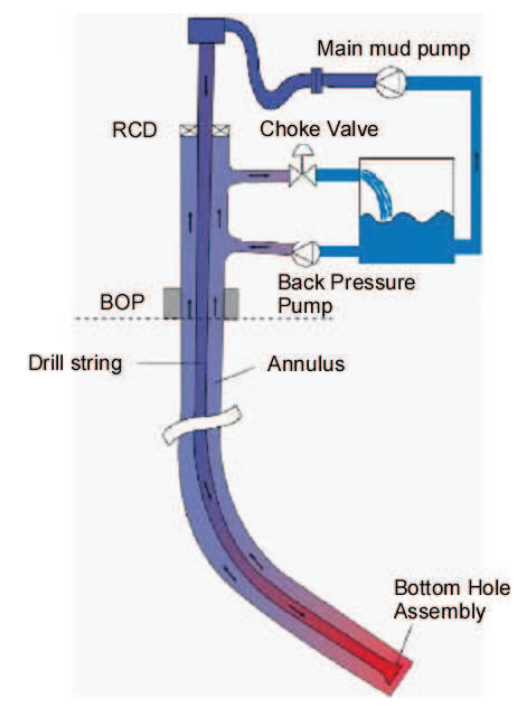

Figure 2: Schematic layout of MPD.

\subsubsection{Well 1: short well with water-based mud}

Well 1 is a vertical well with a total depth of 2300 meter and the water-based drilling fluid density is 1.475 s.g. Further details of the well geometry, the drilling fluid and the reservoir conditions of Well 1 are given in
Table 1. The well is initially in MPD mode, giving a bottomhole pressure of 261 bar. Prior to the kick incident, the main pump is running at a fixed rate of 2000 $l /$ min and the backpressure pump is running at a fixed rate of $400 \mathrm{l} / \mathrm{min}$. At $t_{k i c k}=300$ seconds a kick incident occurs, resulting in gas influx from the reservoir into the well.

\subsubsection{Well 2: Long well with oil-based mud}

Well 2 is a longer deviated well with oil-based mud, where the total depth is 6700 meter and the oil-based drilling fluid density is 1.670 s.g. Further details of the well geometry, the drilling fluid and the reservoir conditions in Well 2 are given in Table 2. The well is in MPD mode, giving a bottomhole pressure of 667 bar. The gas dissolution is ignored.

Throughout the simulations, we assume that a set of good control parameters is already provided. In this work, the good control parameters are obtained by exhaustive simulations. Hence, for each control configuration, we use the parameters, which give the best results among all the exhaustive simulations using the configuration. It should be noted that choosing parameters in the AKC procedure is much easier than that in DSI. In our cases, the control parameters used in AKC for both wells are set as $K_{P}=0.01, K_{I}=0.05$, $K_{f}=0$ during the normal drilling operation with constant bottomhole pressure control and $K_{P}=50$, $K_{I}=0.5, K_{f}=0$ during the kick handling. In DSI, the PI gains are tuned for different conditions, including normal constant bottomhole pressure control, shutin pumps, start-up pumps, constant backpressure control, and constant pump pressure control. In general, the proposed control can be robust against some disturbances if it is properly tuned.

Initially, an MPD operation is in progress in drilling mode. Prior to the kick incident, the main mud pump is running at a fixed rate of $2000 \mathrm{l} / \mathrm{min}$ and the backpressure pump is running at a fixed rate of $400 \mathrm{l} / \mathrm{min}$. At $t_{k i c k}=300$ seconds for Well 1 and 600 seconds for Well 2 a kick incident occurs, resulting in gas influx from the reservoir into the well. The gas influx is then handled using the two different handling procedures, namely DSI procedure and AKC procedure. During the DSI procedure, the main mud pump and the backpressure pump are shut down and the choke is closed. After the kick is attenuated, the main pump is gradually increased to $600 \mathrm{l} / \mathrm{min}$ and kept at this rate for five minutes, allowing the recorded PWD measurements to be transmitted. In the AKC procedure, the pumps are running with the same speed and the choke valve is automatically controlled. After the kick is attenuated, the choke valve is automatically controlled by the feedback-forward control algorithm, keeping the 
well pressure constant and above the pore pressure in the kick zone.

\begin{tabular}{|l|l|} 
Parameter & Value \\
\hline Well length & $2300 \mathrm{~m}$ \\
True vertical depth & $1720 \mathrm{~m}$ \\
Annulus inner diameter & $0.2445 \mathrm{~m}$ \\
Drillpipe outer diameter & $0.1397 \mathrm{~m}$ \\
Drillpipe inner diameter & $0.1183 \mathrm{~m}$ \\
Open hole length & $291 \mathrm{~m}$ \\
Open hole diameter & $0.2159 \mathrm{~m}$ \\
Mud density & $1.475 \mathrm{sg}$ \\
Mud system & Water based \\
Reservoir start TD & $2290 \mathrm{~m}$ \\
Reservoir height & $2 \mathrm{~m}$ \\
Reservoir pore pressure & $263 \mathrm{bar}$ \\
Reservoir kick-off time & $300 \mathrm{sec}$
\end{tabular}

Table 1: Well geometry and fluid data in Well 1

\begin{tabular}{|l|l|} 
Parameter & Value \\
\hline Well length & $6700 \mathrm{~m}$ \\
True vertical depth & $4120 \mathrm{~m}$ \\
Annulus inner diameter & $0.4508 \mathrm{~m}$ \\
Drillpipe outer diameter & $0.1390 \mathrm{~m}$ \\
Drillpipe inner diameter & $0.1183 \mathrm{~m}$ \\
Open hole length & $200 \mathrm{~m}$ \\
Open hole diameter & $0.2159 \mathrm{~m}$ \\
Oil density & $0.805 \mathrm{sg}$ \\
High gravity density & $4.2 \mathrm{sg}$ \\
Oil-water ratio & 3.160 \\
Mud system & Oil based \\
Reservoir start TD & $6695 \mathrm{~m}$ \\
Reservoir height & $2 \mathrm{~m}$ \\
Reservoir pore pressure & $670 \mathrm{bar}$ \\
Reservoir kick-off time & $600 \mathrm{sec}$
\end{tabular}

Table 2: Well geometry and fluid data in Well 2

\subsection{Influx Control Procedure}

The two well control procedures are described below. Dynamic shut-in prcedure (DSI):

- Start time T0: Choke control for BHP to make $\mathrm{BHP}=$ SetPoint

- Time point T1: influx initiated

- Time point T2: influx detection

- Close BackPressure Pump to 0 in 2 mins $\left(q_{b p p}=0\right)$

- Close MudPump to 0 in 2 mins $\left(q_{\text {pump }}=0\right)$
- Choke control of BHP $=$ SetPoint

- Time point T3: $q_{p u m p}<600 \mathrm{l} / \mathrm{min}$

- Close choke to zero in 45 seconds

- Time point T4: Pumps and choke are fully closed

- Wait several minutes for pressure stabilization and kill influx

- Time point T5:

- Start BackPressure Pump to initial speed in $1 \mathrm{~min}$

- Choke control of $P_{c}=$ Constant (consider friction pressure loss)

- Time point T6: $q_{b a c k}=$ initial speed

- Start Mud Pump to 600 l/min in $1 \mathrm{~min}$

- Choke control of $P_{c}=$ Constant (consider annulus friction pressure loss)

- Time point T7: Keep $q_{\text {pump }}=600 \mathrm{l} / \mathrm{min}$ for 5 mins

- Choke control of $P_{\text {pump }}=$ Constant (consider friction pressure loss)

-5 minutes is for transmission of recorded PWD data

- Time point T8:

- Start MudPump to initial speed in $1 \mathrm{~min}$

- Choke control of BHP = New SetPoint (Estimated pore pressure+safety margin)

Automatic kick control procedure (AKC):

- Start time T0: Choke control of BHP = SetPoint

- Time point T1: influx initiated

- Time point T2: influx detected

- Keep constant MudPump and BackPressurePump as initial speeds

- Choke control of flowrate to make flowrate out $=$ flowrate in

- Choke control of flowrate out $=$ flowrate in for pressure stabilization and influx killed

- Time point T3: Choke control of BHP = New SetPoint (Estimated pore pressure + safety margin) 


\subsection{Results}

This section presents the results from the simulations of a kick scenario. Four cases have been run. In Case 1 and 2, we have used Well 1 to simulate the effect of the DSI and the AKC, respectively. In Case 3 and 4, we have shown the performance in Well 2 from using the DSI and AKC, respectively. When discussing the results, several variables from the various locations of the well should be evaluated together. The results are shown in Figures 3-6, their contents will be presented firstly, and then the results will be discussed further. Figure 3 and Figure 4 show the results from Case 1 and 2 in a short well with water based mud. Figure 5 and Figure 6 show the results from Case 3 and 4 in a long well with oil based mud. Each figure includes the flow rates through the main pump, backpressure pump and the MPD choke, the corresponding choke valve, the mud pump pressure, the backpressure, the bottomhole pressure for the whole simulation, and the reservoir influx.

Prior to the kick incident, the main mud pump is running at a fixed rate of $2000 \mathrm{l} / \mathrm{min}$ and the backpressure pump is running at a fixed rate of $400 \mathrm{l} / \mathrm{min}$. The kick situation initiates at time $\mathrm{T} 1=300$ sec. Since the flow rate out of the well can be measured relatively accurately e.g. using a Coriolis flow meter, the increase in flow can be monitored for detection of a possible kick. When the flow out of the well increases, the flow through the choke also increases, and results in an increased choke pressure between time $\mathrm{T} 1$ and T2. This also causes both the bottomhole pressure and the standpipe pressure to decrease since the automatic control system is designed to maintain a constant bottomhole pressure. At time T2, this situation is diagnosed as a possible kick situation. When the possible kick situation is detected, the two different kick control procedures are initiated.

The DSI procedure starts at time T2 by shutting down the backpressure pump and the mud pump in 2 minutes. The choke is then closed completely during 48 seconds at time T3 when the mud pump flow rate is less than $600 \mathrm{l} / \mathrm{min}$, since there is no downhole pressure measurement available. The well is fully shutin at time T4. The bottomhole pressure will then increase and stabilize when the bottomhole pressure equals pore pressure. The choke pressure and the mud pump pressure are recorded. After time T5, the backpressure pump is started gradually to the rate of 400 $\mathrm{l} / \mathrm{min}$ in 1 minute, which is the same value as before the shut-in procedure. The main pump is then started to the rate of $600 \mathrm{l} / \mathrm{min}$ at time T6 in 1 minute and kept at this speed for 5 minutes. From T5 to T8, the automatic control system is designed to maintain constant choke pressure, which depends on the previ- ous recorded choke pressure and the calculated friction pressure loss in the annulus. The time between T7 and $\mathrm{T} 8$ is used for buffering the high-resolution PWD data. The pore pressure of the reservoir kick zone is evaluated based on the recorded bottomhole pressure measurement. After time T8, the main pump rate is increased to the rate of $2000 \mathrm{l} / \mathrm{min}$, which was the speed before the shut-in procedure. The new set-point reference for bottomhole pressure is calculated based on the estimated pore pressure and a pre-defined safety margin. The influx is sufficiently small that it is within the limits of MPD surface equipment to circulate the influx out safely while maintaining well control. The circulation of gas is not the focus of this work.

When comparing the procedures, it can be seen that the influx is larger when using the DSI compared to the AKC. In Well 1, the total kick size is approximately 800 liters when using DSI and 450 liters when using AKC. In Well 2, the total kick size is approximately 2000 liters when using DSI and 500 liters when using $\mathrm{AKC}$. The reason is that $\mathrm{AKC}$ increases pressure more rapidly than DSI and also results in less pressure variations downhole. In addition, the tuning of control parameters in DSI is more complicated compared to the tuning in AKC due to more disturbances and uncertainties in the DSI procedure, such as the disturbance when changing the main pump flow rate, the large sampling time and the delay for the transmission of data is also a factor.

\section{Conclusion}

This paper evaluates two well control procedures adapted to backpressure MPD: The dynamic shutin (DSI) procedure and the automatic kick control (AKC) procedure. Both methods capitalize on improvements in Pressure While Drilling (PWD) technology. A new commercially available PWD tool buffers high-resolution pressure measurements, which can be used in an automated well control procedure. Typically, only minimum, maximum and average downhole pressure is transmitted to surface after circulation is regained. Using new PWD technology, recorded measurements at $0.5 \mathrm{~Hz}$ can be transmitted after regaining circulation. By using backpressure MPD, the choke opening is tuned automatically using a feedbackfeedforward control method.

An feedback-feedforward control algorithm is developed to maintain BHP at the desired set-point and attenuate an influx in MPD operations. The two procedures, DSI and AKC, are evaluated using a high fidelity well flow simulator and cases from a North Sea drilling operation are simulated. The results show that using AKC procedure reduces the time needed to es- 


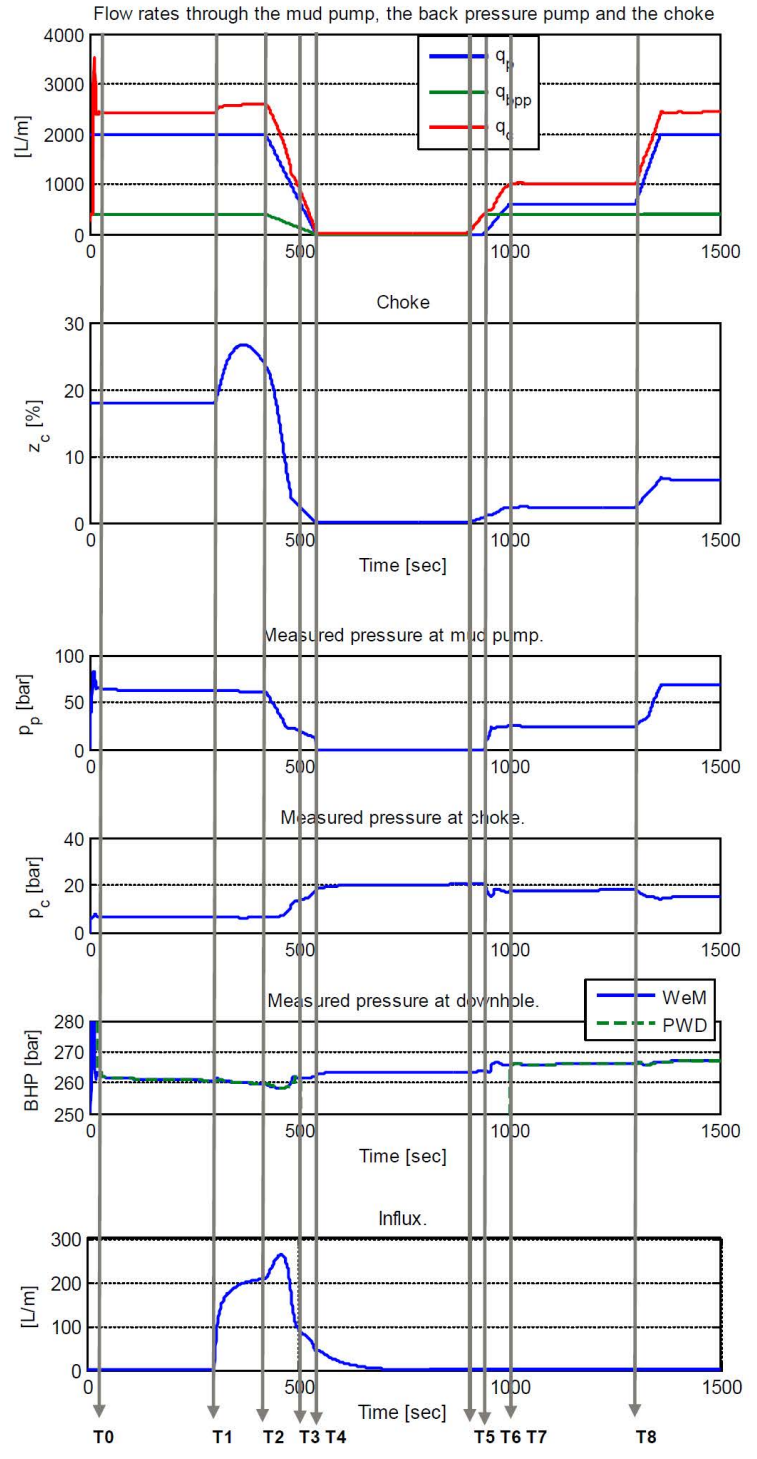

Figure 3: Case 1: Flowrates, choke opening, measured pressure and Influx flow rate using DSI on Well 1.

tablish control of the well, the total kick size, and the risk of lost circulation compared to DSI procedure in our cases.

\section{Acknowledgments}

The authors acknowledge the Research Council of Norway, ConocoPhillips, Det norske oljeselskap, Lundin Norway, Statoil and Wintershall for financing the work through the research centre DrillWell - Drilling and Well Centre for Improved Recovery, a research cooperation between IRIS, Norwegian Univereity of Science and Technology (NTNU), SIINTEF and University of

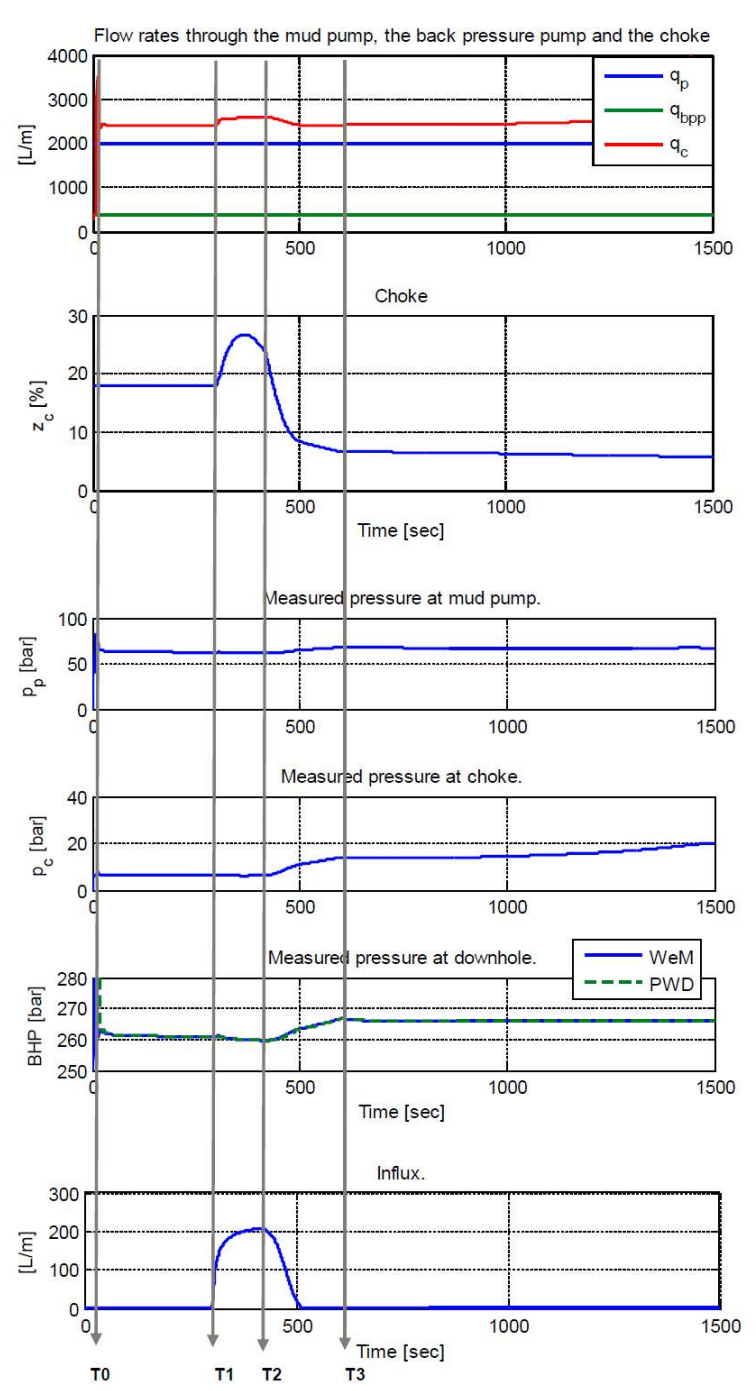

Figure 4: Case 2: Flowrates, choke opening, measured pressure and Influx flow rate using $\mathrm{AKC}$ on Well 1.

Stavanner.

\section{References}

Bacon, W., Tong, A. Y., Gabaldon, O. R., Sugden, C., and Suryanarayana, P. An improved dynamic well control response to a gas influx in managed pressure drilling operations. In IADC/SPE Drilling Conference and Exhibition, SPE-151392. San Diego, California, USA, 2012. doi:10.2118/151392-ms.

Breyholtz, Ø., Nygaard, G., Godhavn, J.-M., and Vefring, E. H. Evaluating control designs for co-ordinating pump rates and choke valve during managed pressure drilling operations. In 


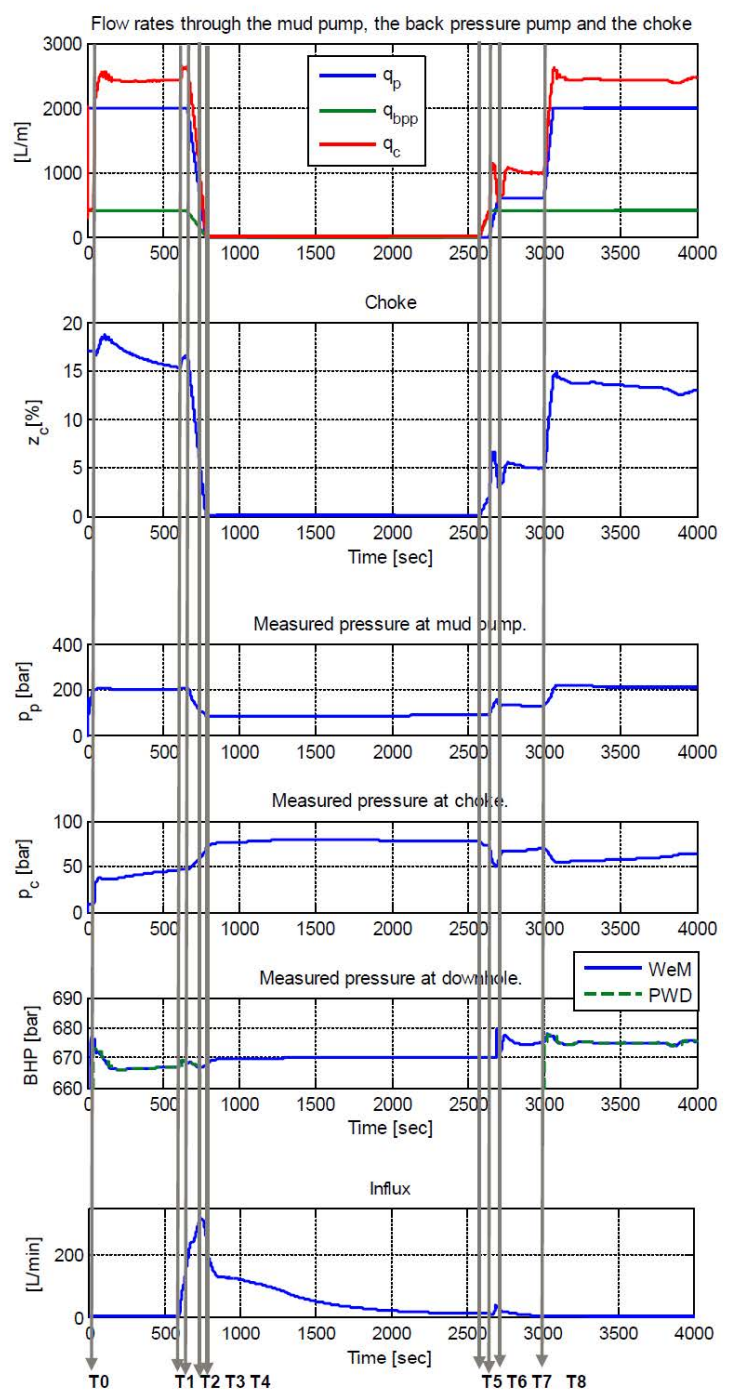

Figure 5: Case 3: Flowrates, choke opening, measured pressure and Influx flow rate using DSI on Well 2.

IEEE International Conference on Control and Applications. Russia, pages 731 - 738, 2009. doi:10.1109/CCA.2009.5281013.

Carlsen, L. A., Nygaard, G., Gravdal, J. E., Nikolaou, M., and Schubert, J. Performing the dynamic shutin procedure becasue of a kick incident when using automatic coordinated control of pump rates and chokevalve opening. In SPE/IADC managed Pressure Drilling and Underbalanced Operations Conference and Exhibition, SPE 113693. Abu Dhabi, UAE, 2008.

Davoudi, M., Smith, J., and Chirinos, J. Evaluation of alternative initial responses to kicks taken during

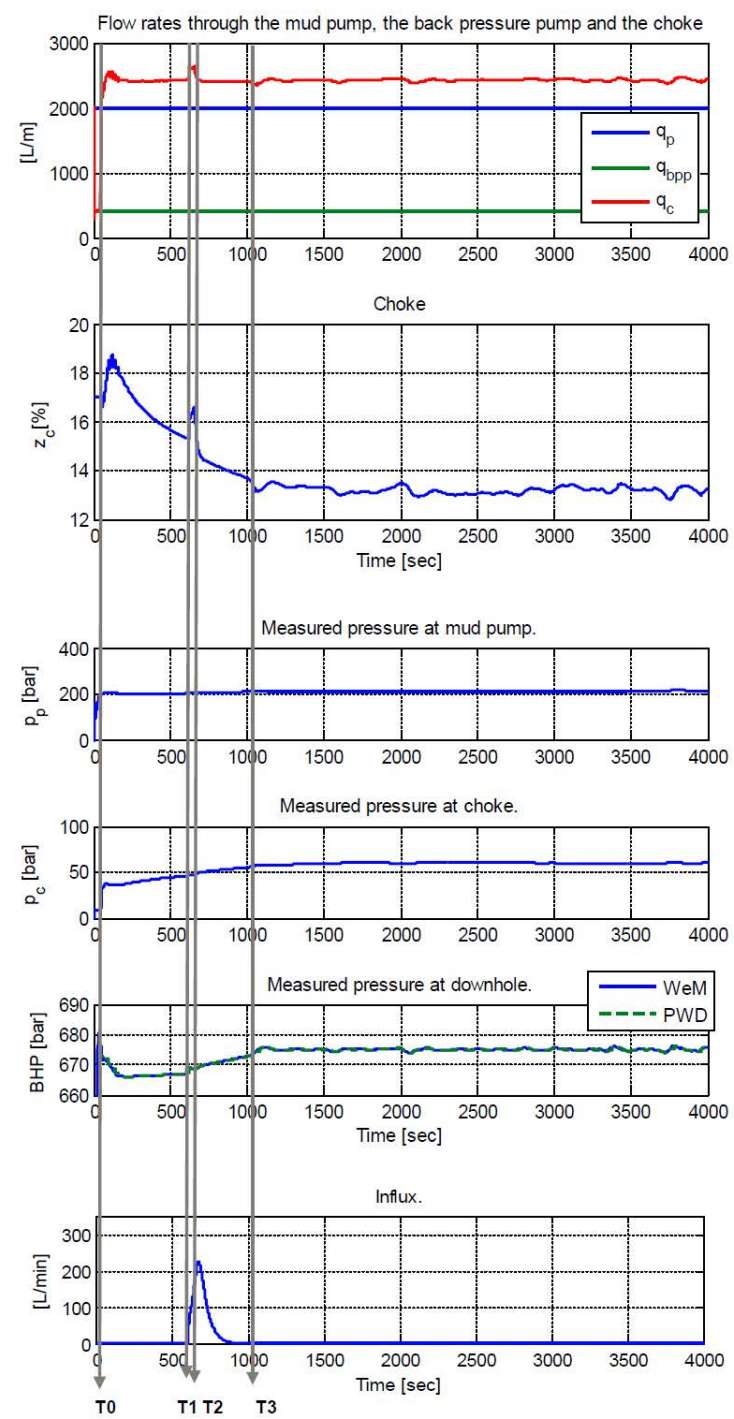

Figure 6: Case 4: Flowrates, choke opening, measured pressure and Influx flow rate using $\mathrm{AKC}$ on Well 2.

managed-pressure drilling. SPE Drilling $\&$ Completion, SPE-128424-MS, 2011. 26(2):194-203.

Godhavn, J.-M. Control requirements for high-end automatic MPD operations. In SPE/IADC Drilling Conference and Exihibition, SPE 119442. Amsterdam, Neitherlands, 2009. doi:10.2118/119442-ms.

Gravdal, J. E., Lorentzen, R., Fjelde, K., and Vefring, E. Improved kick management during MPD by realtime pore-pressure estimation. SPE Drilling \& Completion, SPE 124054, 2010. 25:577-584.

Hannegan, D., Todd, R. J., Pritchard, D. M., and Jonasson, B. MPD uniquely applicable to methane 
hydrate drilling. In SPE/IADC Underbalanced Technology Conference and Exhibition, SPE 91560. Houston, Texas, U.S.A., 2004. doi:10.2118/91560ms.

Kaasa, G. O., Stamnes, Ø. N., Imsland, L., and Aamo, O. Simplified hydraulics model used for intelligent estimation of downhole pressure for a managedpressure-drilling control system. SPE Drilling 86 Completion, SPE 143097, 2013. 27:127-138.

Lage, A., Frøyen, J., and Saevareid, O. Underbalanced drilling dynamics: Two-phase flow modeling and experiments. In IADC/SPE Asia Pacific Drilling Technology, SPE -62743-MS. Kuala Lumpur, Malaysia, 2000.

Lorentzen, R. and Fjelde, K. Use of slopelimiter techniques in traditional numerical methods for multiphase flow in pipelines and wells. International Journal for Numerical Methods in Fluids, 2005. 48:723745. doi:10.1002/fld.952.

Nygaard, G., Vefring, E. H., Fjelde, K.-K., Nævdal, G., Lorentzen, R. J., and Mylvaganam, S. Bottomhole pressure control during drilling operations in gas-dominant wells. SPE Journal, SPE-91578-PA, 2007. 12:49-61.

Santos, H., Catak, E., Kinder, J., and Sonnemann, P. Kick detection and control in oil-based mud: Real well-test results using micro-flux control equipment. In SPE/IADC Drilling Conference, SPE 105454. Amsterdam, Netherlands, 2007.

Santos, H., Leuchtenberg, C., and S.Shayegi. Microflux control:the next generation in drilling process for ultra-deepwater. In Offshore Technology Conference. Houston, Texas, USA, 2003. doi:10.4043/15062-MS.

Siahaan, H. B., Bjrkevoll, K. S., and Gravdal, J. E. Possibilities of using wired drill pipe telemetry during managed pressure drilling in extended reach wells. In SPE Intelligent Energy Conference and Exhibition, SPE 167856. Utrecht, Netherlands, 2014.

Smith, J. R. and Patel, B. M. A proposed method for planning the best initial response to kicks taken during managed-pressure-drilling operations. SPE Drilling \& Completion, SPE-143101-PA., 2012. 27(2):194-203.

Zhou, J. and Nygaard, G. Control and estimation of downhole pressure in managed pressure drilling operations. In Proceedings of the 4 th International Symposium on Communications, Control and Signal Processing. Limassal, Cyrpus, 2010. doi:10.1109/isccsp.2010.5463474.

Zhou, J. and Nygaard, G. Automatic model-based control scheme for stabilizing pressure during dual gradient drilling. Journal of Process Control, 2011. 21:1138-1147. doi:10.1016/j.jprocont.2011.06.022.

Zhou, J., Nygaard, G., Godhavn, J.-M., Breyholtz, Ø., and Vefring, E. H. Adaptive observer for kick detection and switched control for bottomhole pressure regulation and kick attenuation during managed pressure drilling. In Proceedings of American Control Conference. USA, 2010. doi:10.1109/ACC.2010.5531551.

Zhou, J., Stamnes, Ø. N., Aamo, O. M., and Kaasa, G.-O. Pressure regulation with kick attenuation in a managed pressure drilling system. In Proceedings of the 48th IEEE Conference on Decision and Control. Shanghai, China, 2009. doi:10.1109/CDC.2009.5400792.

Zhou, J., Stamnes, Ø. N., Aamo, O. M., and Kaasa, G.O. Switched control for pressure regulation and kick attenuation in a managed pressure drilling system. IEEE Transactions on Control Systems Technology, 2011. 19:337-350. doi:10.1109/TCST.2010.2046517. 